\title{
Detection of Chlamydia trachomatis-specific antibodies in human sera by recombinant major outer-membrane protein polyantigens
}

\author{
PER MYGIND, GUNNA CHRISTIANSEN, KENNETH PERSSON* and SVEND BIRKELUND \\ Department of Medical Microbiology and Immunology, University of Aarhus, DK-8000 Aarhus, Denmark and \\ * Department of Virology, University Hospital, Malmö, Sweden
}

\begin{abstract}
This study was performed to generate and evaluate recombinant antigens for use in a species-specific Chlamydia trachomatis immunoassay. In a molecular genetic approach, fragments of the $C$. trachomatis major outer-membrane protein (MOMP) were produced as fusion proteins to create three different constructs encompassing the variable domains I, II and IV of selected $C$. trachomatis serovars. The recombinant MOMP polyantigens were affinity-purified and used in an enzyme-linked immunosorbent assay. Antibody detection was evaluated with 103 patient sera and the results were compared with titres obtained in the micro-immunofluorescence test. The results showed that the generated MOMP polyantigens detected the presence of $C$. trachomatis-specific human antibodies with little cross-reaction to $C$. pneumoniae-specific antibodies. When compared to the micro-immunofluorescence assay the MOMP polyantigen detected the presence of anti- $C$. trachomatis IgG antibodies with a sensitivity of $80 \%$ and a specificity of $91 \%$.
\end{abstract}

\section{Introduction}

The eubacterial genus Chlamydia comprises a group of obligately intracellular pathogens that proliferate through a unique biphasic developmental cycle. The organisms alternate between an infective (elementary body, EB) and a replicating form (reticulate body, RB). The genus consists of four species $-C$. trachomatis, $C$. pneumoniae, C. pecorum and C. psittaci. C. trachomatis and $C$. pneumoniae cause a wide variety of infections in man, wherease C. psittaci and C. pecorum are animal pathogens of particular interest in veterinary medicine. Occasionally, $C$. psittaci causes severe infections of the respiratory tract in man known as psittacosis or ornithosis.

C. trachomatis is divided into serovars, all of which are human pathogens except the mouse pneumonitis serovar (MoPn). The trachoma biovars (serovars AC) cause conjunctivitis, leading to trachoma, the primary cause of preventable blindness in third world countries. Serovars D-K are all pathogens of the urogenital tract. They are the most common cause of sexually transmitted genital infections, eliciting local

Received 16 Aug. 1999; revised version received 20 Oct. 1999; accepted 21 Oct. 1999.

Corresponding author: Dr P. Mygind (e-mail: perm@ biobase.dk). acute epithelial infections, which can lead to pelvic inflammatory disease. Chronic infections by C. trachomatis serovars D-K occasionally cause tubal obstruction or ectopic pregnancy. The serovars L1-L3 of $C$. trachomatis infect both macrophages and epithelial cells and are spread systemically through the lymphatic tissue, causing the invasive disease known as lymphogranuloma venereum [1].

C. pneumoniae causes pneumonia, bronchitis and pharyngitis [2]. Recently, this human pathogen has been associated with chronic disease such as asthma, chronic bronchitis, acute myocardial infarction and coronary artery disease [3-5]. Studies show that antiC. pneumoniae antibodies are widespread in the adult population $(\sim 50 \%)[6]$.

The aim of this study was to develop a serological assay able to measure specific antibodies to $C$. trachomatis genital serovars with little cross-reaction to $C$. pneumoniae-specific antibodies. In cases of upper genital tract infection, it is important to use serology tests that can distinguish antibodies to $C$. trachomatis from those associated with non-genital chlamydiae. This is the main problem of Chlamydia serology today. A large retrospective study showed that antibodies to C. pneumoniae account for up to half of all chlamydia IgG-positive patients attending genitourinary medicine clinics [7]. Similar results were obtained when 
analysing sera from anti-chlamydia IgG-positive rheumatological patients [8]. The main reason for this is the low specificity of commonly used chlamydial serology tests.

The chlamydial micro-immunofluorescence test (MIF) is the only differential serodiagnostic tool generally applied [9]. This test is based on the measurement of antibodies to surface-exposed membrane components of purified Chlamydia serovars. The outer membrane of Chlamydia spp. consists primarily of the major outermembrane protein (MOMP), outer-membrane protein 2 (Omp2), outer-membrane protein 3 (Omp3) and a loosely associated genus-specific lipopolysaccharide (LPS). MOMP, Omp2 and LPS have been identified as the major immunodominant chlamydial antigens $[10,11]$.

The only commercially available recombinant chlamydia serology test is based upon LPS (Medac, Germany). LPS is highly immunogenic in human chlamydial infections as it contains a surface-exposed epitope. The epitope is genus-specific and is, therefore, not suitable as an antigen in chlamydial species-specific serology $[12,13]$.

Omp2 is a general target of the immune system in both C. trachomatis and C. pneumoniae infections [10, $11,14]$. An analysis of the humoral immune response towards recombinant Omp2 has nevertheless failed to detect any species-specific epitopes [15]. No surface exposure of the protein has been detected [16-18].

MOMP is a primary target of serovar-specific antibodies [19]. It is considered to be a porin, spanning the outer membrane of all Chlamydia species. Infections with $C$. trachomatis induce a strong humoral response mainly directed against three variable, surface-exposed segments of this protein (VS-I, VS-II and VS-IV) $[20,21]$. These regions are also the basis of the $C$. trachomatis serovar typing. C. pneumoniae MOMP does not seem to be surface exposed and it is less immunogenic in infections caused by this pathogen $[22,23]$. Therefore, MOMP is an obvious candidate in a C. trachomatis-specific serological assay. Unfortunately, MOMP harbours non-resolved immunoglobulinbinding properties, making the mature protein less suitable for chlamydial serology [11].

The present study selected and purified C. trachomatisspecific immunodominant regions of MOMP as recombinant polyantigens (VS-I, VS-II and VS-IV). Fusion proteins that were generated were applied in a C. trachomatis-specific serological assay. The study analysed the presence of $\mathrm{IgG}$ antibodies against these MOMP polyantigens in a wide panel of human sera with different serological evidence of $C$. trachomatis, C. pneumoniae or no chlamydial infection. Results obtained by enzyme-linked immunosorbent assay (ELISA) were compared to the 'gold' standard of chlamydial serology, the MIF test [9]. Preliminary results of this study were presented at the Ninth International Symposium on Human Chlamydial Infections [24].

\section{Materials and methods}

\section{Chlamydial strains}

C. trachomatis serovar E was obtained from the American Type Culture Collection (ATCC). Strains used in the MIF protocol have been described previously [25].

\section{Serum samples}

Serum samples were collected from genitourinary clinic patients, patients with suspected ornithosis and from apparently healthy, asymptomatic donors.

\section{MIF}

The protocol used to obtain MIF results has been described previously [25]. C. pneumoniae IOL-207, C. psittaci $6 \mathrm{BC}$ and $C$. trachomatis serovars $\mathrm{D}-\mathrm{K}$ were included in the assay. End-point titrations of reactive sera were performed and geometric mean titres were calculated for positive sera. Titres $\geqslant 16$ were considered positive by the assay.

\section{Characterisation of human sera by MIF}

Sera were sorted into four groups, according to serum reactivity as measured by MIF with fixed whole cells of C. trachomatis and C. pneumoniae. Sera of group I (positive for both $C$. pneumoniae and C. trachomatis by MIF) were selected from women who were culturepositive for $C$. trachomatis (19 sera). Group II consisted of sera from normal healthy women who had been screened by MIF for anti-chlamydial antibodies and found to be positive for C. trachomatis only (20 sera). Sera from patients examined for $C$. pneumoniae infection or onithosis where only anti- $C$. pneumoniae antibodies had been found constituted group III (19 sera). This group also included 11 sera from apparently healthy donors (asymptomatic patients). Sera without anti-chlamydial antibodies (MIF) at routine screening constituted the fourth group (34 sera).

\section{Cloning of momp gene fragments into expression vector pET9d-6His}

Gene fragments encoding a 6-mer histidine tag and selected regions of $C$. trachomatis momp genes were introduced into the expression vector pET9d [26, 27]. Four pairs of oligonucleotides (Table 1) were used in the cloning strategy, which is outlined in Fig. 1. The oligonucleotides were synthesised by DNA Technology, Denmark. 
Table 1. Oligonucleotides used to generate recombinant MOMP polyantigens

\begin{tabular}{|c|c|c|}
\hline $\begin{array}{l}\text { Oligonuclotide } \\
\text { set }\end{array}$ & Oligonucleotide sequences & Encoded protein fragment \\
\hline H & 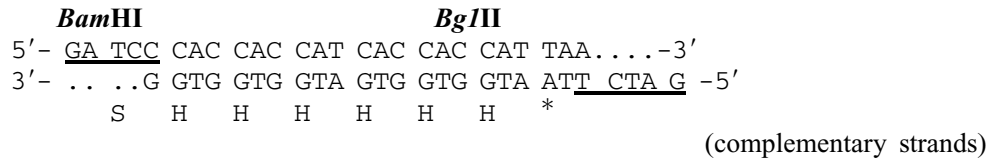 & $\begin{array}{l}\text {-SHHHHHH* } \\
\text { (C-term Histag) }\end{array}$ \\
\hline 1 & 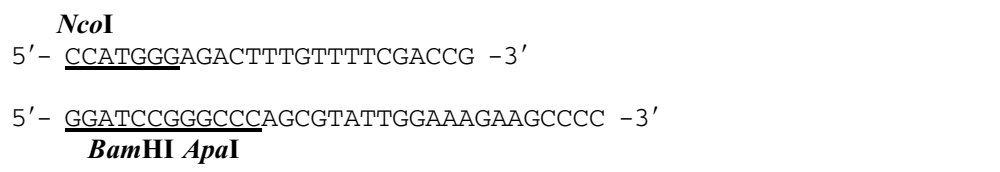 & $\begin{array}{l}\text { C. trachomatis } \\
\text { serovar E } \\
\text { MOMP }_{\text {aа66-aa216 }}\end{array}$ \\
\hline 2 & 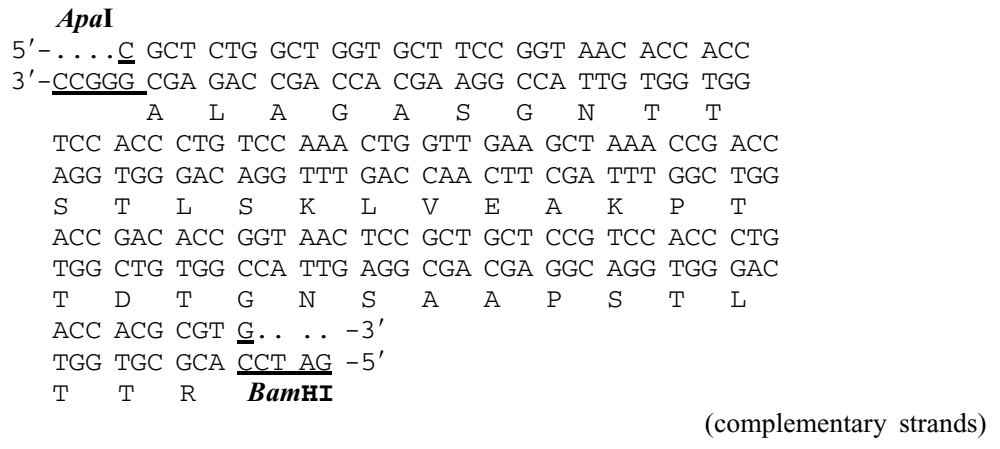 & $\begin{array}{l}\text { C. trachomatis } \\
\text { serovar D-F/G } \\
\text { MOMP }_{\text {aa } 86 / 87-a a 102 / 104}\end{array}$ \\
\hline 3 & 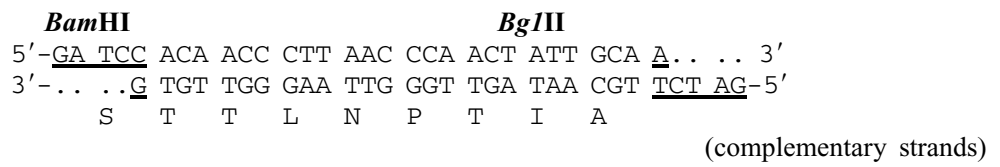 & $\begin{array}{l}\text { C. trachomatis } \\
\text { serovar E } \\
\text { MOMP }_{\text {aа317-aa324 }}\end{array}$ \\
\hline
\end{tabular}

A gene fragment encoding a 6-mer histidine tag used in subsequent purification of fusion proteins was initially introduced into the Bam HI restriction endonuclease cleavage site of plasmid pET9d (Fig. 1, step 1). The oligonuclotide set $\mathrm{H}$ is made up of complimentary strands, creating an upstream Bam HI sequence overhang and a downstream identical $B g l$ II sequence overhang (Table 1). The pET9d vector was digested with Bam HI and re-ligated by using the T4 DNA-ligase in the presence of equimolar amounts of oligonuclotide set $\mathrm{H}$ [26] (Boehringer Mannheim $\mathrm{GmbH}$, Germany). Recombinant pET9d plasmids were electrotransformed into Escherichia coli XLI-blue competent cells and purified by alkaline lysis of recombinant bacteria [26]. Selected plasmids were DNA sequenced to ensure the correct orientations and nucleotide content of the introduced fragment. This was done bidirectionally with plasmid-specific primers, the ABI Prism dye terminator cycle sequencing ready reaction kit and an ABI Prism 377 DNA sequencer as described by the manufacturer (Perkin-Elmer, CT, USA). Upon ligation of oligonuclotide set $\mathrm{H}$ into pET9d, only one Bam HI restriction endonuclease site is maintained (upstream of the encoded histidine tag).

By using the Nco I restriction endonuclease site of the pET9d vector located further upstream of the introduced histidine-encoding gene fragment and the generated $B a m \mathrm{HI}$ restriction endonuclease site, it was possible to include a specific momp sequence upstream of the histidine-encoded fragment maintaining the correct reading frame. C. trachomatis serovar E is the most widespread genital strain, causing c. $38-52 \%$ of C. trachomatis urogenital infections [28-30]. PCR with C. trachomatis serovar E genomic DNA and primer set 1 was used to amplify the momp gene fragment encoding $C$. trachomatis serovar E $\mathrm{MOMP}_{\mathrm{aa} 66-\mathrm{a} 216}$ (Fig. 2, Table 1). The PCR protocol used included 30 amplification cycles $\left(30 \mathrm{~s}\right.$ at $94^{\circ}, 30 \mathrm{~s}$ at $50^{\circ} \mathrm{C}$ and $30 \mathrm{~s}$ at $72^{\circ} \mathrm{C}$ ) (Boehringer Mannheim $\mathrm{GmbH}$ ). The PCR product was ligated into $\mathrm{pCR}^{\mathrm{TM}}$-II vector and recombinants were transformed into $E$. coli $\mathrm{INV}_{\mathrm{N}} \mathrm{F}^{\prime}$ as described (Invitrogen, USA). After plasmid isolation and DNA sequencing, the amplified DNA fragment was moved into the histidine-encoding plasmid by digestion of both the recombinant $\mathrm{pCR}^{\mathrm{TM}}-\mathrm{II}$ vector and the histidine-encoding pET9d with $N c o$ I/Bam HI restriction endonucleases and subsequent re-ligation with $\mathrm{T} 4$ DNA-ligase (Boehringer Mannheim GmbH) (Fig. 1, step 2) [26]. By transformation of recombinant plasmid in E. coli XL-I blue and selecting for kanamycin resistance (present in the pET9d vector), clones harbouring the plasmid encoding antigen 1 were obtained (Fig. 2). In addition to the upstream Nco I site and a downstream Bam $\mathrm{HI}$ site, an Apa I restriction endonuclease site was introduced downstream of the momp encoding sequence, to facilitate subsequent cloning of the fusion construct (Table 1, Fig. 1).

Epidemiological studies have shown that C. trachomatis serovars D, E, F and G are responsible for $83-86 \%$ of all C. trachomatis genital infections [28-30]. To 


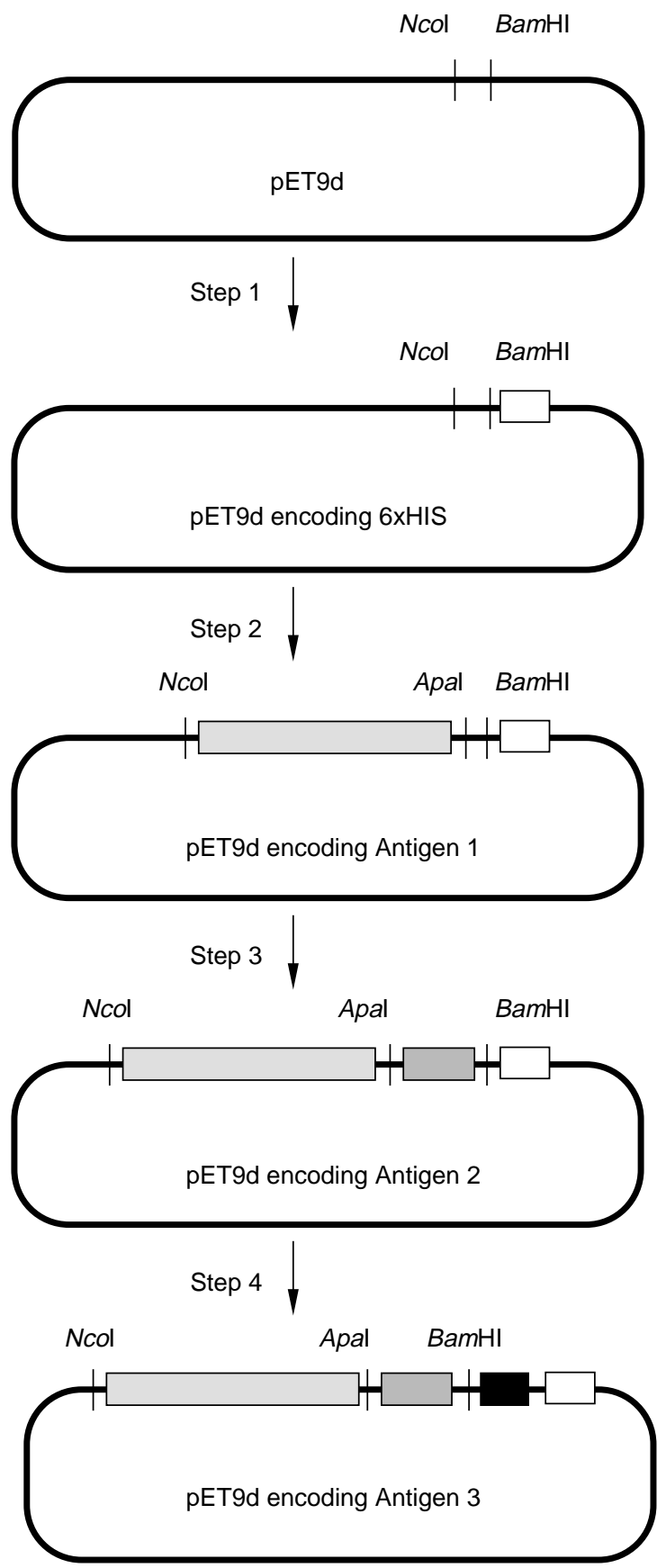

Fig. 1. Illustration of the cloning strategy applied to create the plasmid constructs encoding antigens $1-3$ used in this study. Step 1: digestion of plasmid pET9d with Bam HI and re-ligation with phosphorylated, complementary oligonuclotide set H. Step 2: Nco I/Bam HI digestion of plasmid pET9d and re-ligation with PCR fragment amplified by primer set 1. Step 3: digestion with ApaI/Bam HI and re-ligation with phosphorylated oligonuclotide set 2. Step 4: Bam HI digestion and re-ligation with phosphorylated, complementary oligonuclotide set 3. See Materials and methods for details. Colours used in this illustration are as given for Fig. 2.

allow detection of antibodies against heterologous $C$. trachomatis serovars, a gene fragment encoding the MOMP VS-I regions of serovars $\mathrm{F} / \mathrm{G}$ (identical regions, ${ }^{87}$ ALAGASGNTTSTLSKLVE ${ }^{104}$ ) and serovar D $\left({ }^{86}\right.$ AKPTTDTGNSAAPSTLT $\left.{ }^{102}\right)$ was introduced (Fig. 2). (Jones et al. have reported that this region is recognised by antibodies in sera from trachoma patients [21].) This was done by synthetically producing a set of oligonucleotides encoding both momp fragments (Table 1 , oligonuclotide set 2 ). These complementary oligonucleotides were synthesised to include an upstream Apa I and a downstream Bam $\mathrm{HI}$ sequence overhang. This fragment was introduced into the fusion protein construct encoding antigen 1, by ApaI/Bam HI digestion of the plasmid and re-ligation in the presence of the oligonuclotide set 2 (Table 1; Fig. 1, step 3). Correct cloning was ensured by DNA sequencing of resulting recombinant plasmids.

MOMP VS-IV is recognised by neutralising murine monoclonal antibodies (MAbs) [20]. Therefore, a gene fragment encoding C. trachomatis $\mathrm{MOMP}_{\text {aa317-aa324 was }}$ included in the final fusion protein construct (Fig. 2). This region is conserved in all genital serovars of $C$. trachomatis except for serovar $\mathrm{K}$ and is very different from the homologous regions of both $C$. pneumoniae and C. psittaci MOMP (Fig. 2). The variable segment IV of C. psittaci MOMP has been successfully applied in the serological detection of abortigenic C. psittaci infection in ruminants [31]. The coding region was generated by oligonuclotide set 3 and as in the initial cloning of the histidine fragment, upstream $\mathrm{Bam} \mathrm{HI}$ and downstream $B g l$ II restriction endonuclease sequence overhangs were introduced (Table 1). The plasmid construct encoding antigen 2 was digested with Bam HI and re-ligated in the presence of oligonuclotide set 3 (Fig. 1, step 4). Sequencing of the resulting construct demonstrated that this final plasmid contained the sequence encoding antigen 3 (Fig. 2).

\section{Production and purification of fusion proteins}

To express and purify plasmid-encoded fusion proteins, the recombinant pET9d vectors were electrotransformed into E. coli BL21-DE3. Cultures were grown in the presence of kanamycin $(30 \mu \mathrm{g} / \mathrm{ml})$. During logphase growth, the bacterial production of pET9dencoded fusion proteins was induced with isopropyl $\beta$-D-thiogalactoside (IPTG, $0.4 \mathrm{~mm}$ ) [27]. The Cterminal-encoded histidine tag included in all fusion proteins made it possible to purify the recombinant proteins [32] by affinity chromatography under denaturing conditions with a $\mathrm{Ni}^{++}$-NTA resin and a $\mathrm{pH}$ gradient (Quiagen, CA, USA) [15]. The eluates were neutralised with a 1 in 10 volume of $1 \mathrm{M}$ Tris- $\mathrm{HCl}$ buffer $(\mathrm{pH} 8)$ and analysed by SDS-PAGE and Coomassie Blue staining [15].

\section{ELISA}

Antigenicity of purified fusion proteins was measured by ELISA with the selected panel of sera. Polysorb microtration plates (Nunc, Denmark) were coated for $2 \mathrm{~h}$ with $50 \mu \mathrm{l}(5 \mu \mathrm{g} / \mathrm{ml})$ of recombinant protein in $50 \mathrm{mM}$ carbonate buffer ( $\mathrm{pH}$ 9.6). Excess binding capacity was blocked by adding $200 \mu \mathrm{l}$ of fetal calf 
C.trachomatis $A$ C.trachomatis $B$ C.trachomatis Ba C.trachomatis $C$ C.trachomatis $D$ C.trachomatis $E$ C.trachomatis $F$ C.trachomatis $G$ C.trachomatis $H$ C.trachomatis I C.trachomatis $\mathrm{K}$ C.trachomatis $L 1$ C.trachomatis L2 C.trachomatis $L 3$ Amino acid no. C.pneumoniae AR388 C.psittaci $6 B C$
GDFVFDRVLKTDVNKEFQ.M AAPT TRDVAGLEKDPVVNVARPNPAYGKHMODAEMFTNAAYMALNIWDREDVFCTLGATTC DFVFDRVLKTDVNKEF $Q$. MGAKP T T T. TGNAVAP. S TLTARENPAYGRHMQDAEMF TNAACMALN I WDRF DVFCTLGASSG 作 TITARENPAYGRHMO. 作 GDFVFDRVLKTDVNKEFE. MGEALAGA. SGNT TSTLSKLVERTNPAYGKHMQDAEMF TNAACMT LN I WDRF DVFCT L GATSG DFVFDRVLKTDVNKEFQ.MGAAPT TNDAADLQNDPKTNVARPNPAYGKHMQDAEMFTNAAYMALNIWDRFDVFCTLGATTG

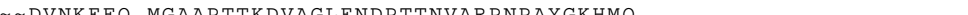
法

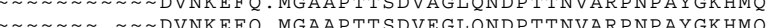

GDFVFDRVLOTDVNKEFO.MGAKPTAT. TGNAAAP. STCTARENPAYGRHMODAEMFTNA. $\ldots \ldots \ldots \ldots \ldots \ldots \ldots$ GDFVFDRVLOTDVNKEF . MGAKP TTA. TGNAAAP. STCTARENPAYGRHMQDAEMF TNAAYMALNIWDRFDVFCTIGATSG GDFVFDRVLQTDVNKEF Q.MGAEPT TSDT AG LSNDP T TNVARPNPAYGKHMODAEMF TNAAYMALNI WDRFDVFCT LGAT TG

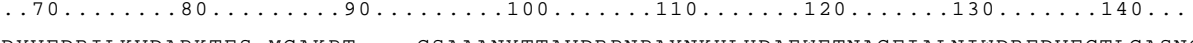
GDYNFDRVLKVDVNKT F GMAATP TQATGNASNTNQPEANGRPNIAYGRHMQDAEWF SNAAF LALNI WDRFDIFCTLGASNG

\section{Variable Segment II}

Variable Segment IV

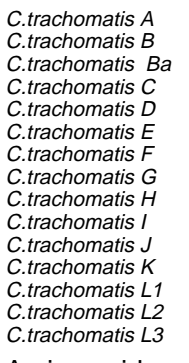

Amino acid no.

Cpneumoniae AR388 C.psittaci $6 B C$

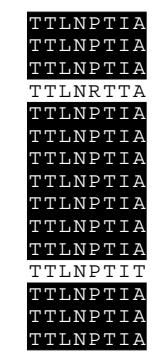

$317 \ldots 324$

TAWNPSLI T T WN P S L I

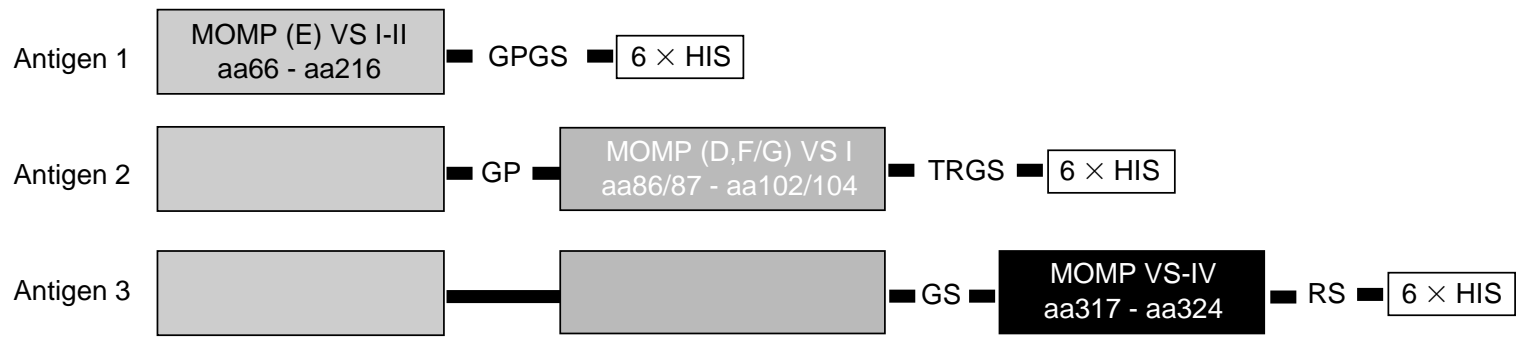

Fig. 2. (a) Multiple alignment of chlamydial MOMP amino acid sequences. Only regions of the protein used in this study are illustrated (variable segments I, II and IV). (b) The compositions of the generated fusion proteins (antigen 1 3 ) are shown. The colour coding refers to the multiple alignment above. Light grey depicts the protein fragment of $C$. trachomatis (E) VS I-II (aa66-aa216). Dark grey depicts $C$. trachomatis D, F/G VS-I (aa86/87-aa102/104). Areas depicted in black show the C. trachomatis-specific VS-IV fragment (aa317-aa324). Amino-acid fragments generated by restriction endonuclease sites used in the cloning strategy are depicted by single letter code between fusion partners.

serum $20 \%$ in phosphate-buffered saline ( $\mathrm{pH} 7.4)$ including Tween-20 $0.05 \% \quad$ (PBS-T) (Sigma). Sera were diluted 1 in 100 in the blocking agent to absorb any cross-reacting antibodies directed against fetal calf serum. Antigen-coated microtitration plates and sera dilutions were stored overnight at $4^{\circ} \mathrm{C}$. Diluted sera were added to the plates and incubated for $2 \mathrm{~h}$. Bound antibody was detected by incubation for $1 \mathrm{~h}$ with peroxidase-labelled goat anti-human IgG (BioRad, CA, USA) diluted 1 in 3000 in PBS-T. Tetramethylbenzidine was the chromogen used in this assay, as described by the manufacturer (Sigma). Incubation was at room temperature and all intermediate steps in the assay were followed by washing the microtitration wells four times in PBS-T. Colour development was terminated after $20 \mathrm{~min}$ by addition of an equal amount of $1 \mathrm{M}$ $\mathrm{HCl}$. Optical density at $450 \mathrm{~nm}\left(\mathrm{OD}_{450}\right)$ was measured on a Bio-Kinetics Reader with the KC3 software program (Bio-Tek Instruments, Winooski, VT, USA). The results are average values of two independent measurements, with SDs of $<10 \%$. In all data presented in this paper, the background $\mathrm{OD}_{450}$ value measured for each serum upon binding to plates without antigen was subtracted from the $\mathrm{OD}_{450}$ measured when antigen was used in the ELISA. This background was in the order of $\mathrm{OD}_{450} \quad 0.0-0.3$. The $\mathrm{OD}_{450}$ cut-off values for each antigen, chosen empirically so as to obtain the highest possible sensitivity and specificity of the ELISA compared to MIF, were 1.5 (antigen 1), 0.8 (antigen 2) and 0.8 (antigen 3). 


\section{DNA sequences}

Chlamydial momp sequences were obtained from the EMBL/GenBank/DDBJ database (accession nos. M58938, M17342, M17343, X52557, X52080, X16007, M36533, M14738, X55700) and from the paper by Yuan et al. [33].

\section{Results}

Production of purified recombinant antigens $1-3$

Three recombinant plasmids encoding MOMP polyantigens were generated by a combined cloning strategy. Antigen 1 contained the variable segment III of C. trachomatis serovar E (MOMP ${ }_{\mathrm{aa} 66-\mathrm{aa} 216}$ ) (Fig. 2). The gene fragment encoding VS-I of serovar $F / G$ and serovar D was introduced in antigen 2 (Fig. 2). The final construct (antigen 3 ) included the gene fragment encoding the species-specific region of $C$. trachomatis MOMP VS-IV (Fig. 2). The intervening sequences encoded by nucleotides of restriction enzyme palindromes between fusion partners are depicted in Fig. 2. All three antigens were purified by nickel-affinity chromatography and analysed by SDS-PAGE (not shown). The antigen preparations were found to be $>95 \%$ pure, as judged by a Coomassie Blue-stained polyacrylamide gel.
Reactivity of sera with recombinant antigens 1-3

To evaluate the efficacy of the purified MOMP polyantigens in detecting species-specific C. trachomatis antibodies, a panel of 103 human sera was tested in duplicate by ELISA. The sera were sorted into four groups according to the presence or absence of $C$. trachomatis or $C$. pneumoniae antibodies, or both, in the samples as measured by MIF. First, the antigen containing $C$. trachomatis serovar E MOMP (VS I-II) was used in the ELISA (antigen 1, Fig. 2). It was found that $>56 \%$ (22 of 39) of C. trachomatis MIF-positive sera were positive by ELISA (serum groups I and II, Fig. 3). In contrast, $80 \%$ (51 of 64) of MIF-negative sera were negative in the ELISA assay (serum groups III and IV, Fig. 3). The species specificity of this antigen is evident, because there was no increase in the positive rate of samples reported positive by $C$. pneumoniae MIF (serum groups I and III) as compared to serum groups II and IV (negative by $C$. pneumoniae MIF) (Fig. 3).

To increase the sensitivity and specificity of the assay, antigen 2 containing, additionally, VS-I from $C$. trachomatis serovars $\mathrm{D}$ and $\mathrm{F} / \mathrm{G}$ was tested (Fig. 2). When this recombinant MOMP polyantigen was used in ELISA, 12 of 19 sera (63\%) that were positive by $C$. trachomatis MIF and culture isolation were positively identified (group I, Fig. 3). In group II (not confirmed

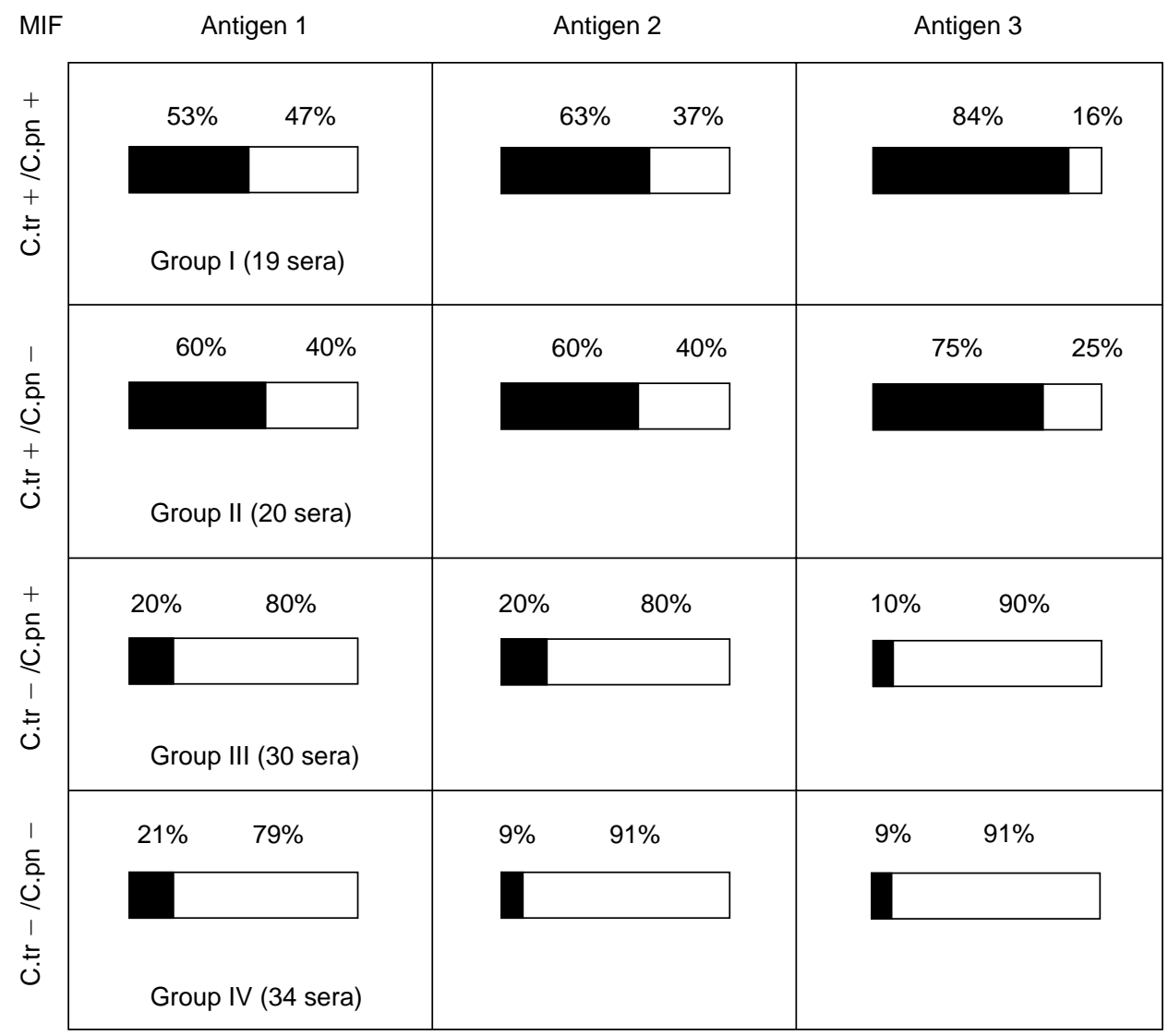

Fig. 3. ELISA results obtained with recombinant MOMP polyantigens 1, 2 and 3. The results are compared with MIF. The percentages of sera positive by ELISA are shown in black, whereas the white colouring shows the percentage considered negative by ELISA. The cut-off $\mathrm{OD}_{450}$ values were $1.5,0.8$ and 0.8 respectively. 
by culture isolation, but $C$. trachomatis positive and $C$. pneumoniae negative by MIF), this antigen gave positive results with 12 of $20(60 \%)$ of the sera (Fig. $3)$. In the group of $C$. trachomatis/C. pneumoniae MIF-negative sera (serum group IV, Fig. 3) there was a decrease in the false-positive detection of sera. In all, antigen 2 was superior to antigen 1 in the detection of C. trachomatis-specific antibodies, as both sensitivity and specificity were enhanced.

Finally, to generalise the species-specificity of the assay, antigen 3 was tested (Fig. 2). By including the species-specific MOMP fragment VS-IV in the polyantigen, the ELISA detection of the $C$. trachomatis MIF-positive sera was clearly increased (groups I and II, Fig. 3).

Comparison of results obtained by MIF and ELISA with antigen 3

The qualitative correlation between results obtained by ELISA with antigen 3 and the results of C. trachomatis
MIF was analysed. The sensitivity of this antigen was close to $80 \%$, as 31 of 39 C. trachomatis MIF positive sera were positively identified in this third assay. The specificity of this assay was $91 \%$, as 58 of 64 sera were negative by both $C$. trachomatis MIF and the ELISA with antigen 3 . The quantitative ELISA results with antigen 3 were correlated with $C$. trachomatis MIF titres of all sera, and the results are presented in Fig. 4. There was no statistical correlation between MIF titres and antibodies measured in this assay $(\mathrm{p}>0.05)$, but a trend was evident (Fig. 4). Sera with higher MIF titres gave higher $\mathrm{OD}_{450}$ values in the ELISA.

\section{Discussion}

Serology has provided important information regarding the wide range of disease associated with $C$. trachomatis infection, including infant pneumonia, acute reactive arthritis and chronic genital infections. Whole-cell chlamydia organisms and particularly the MIF assay have generally been applied in the species-

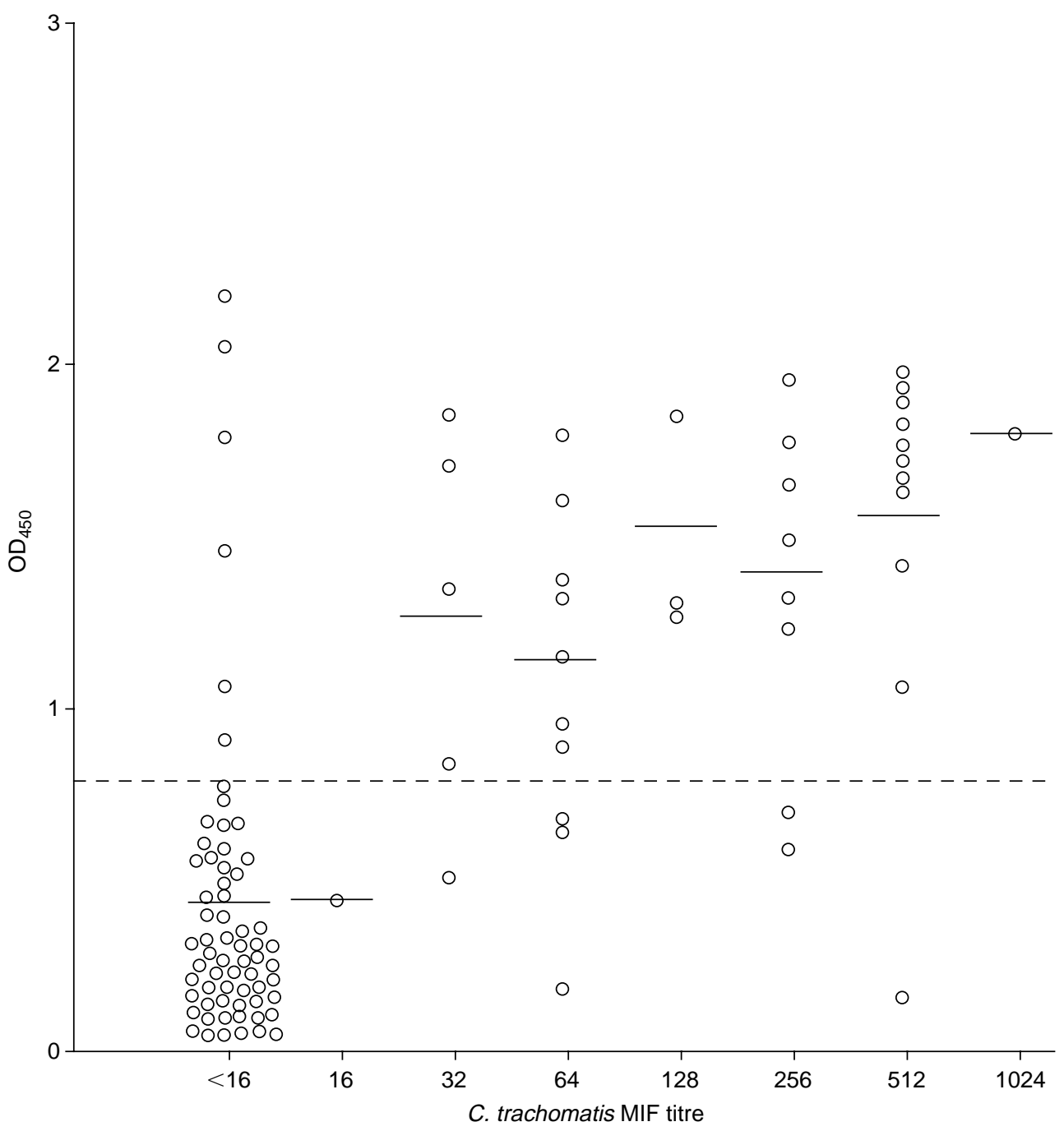

Fig. 4. The quantitative relationship between titres obtained with $C$. trachomatis antigen in MIF and ELISA readings with recombinant antigen 3. Sera were diluted 1 in 100 in the ELISA measurements. Each circle represents one serum. The mean $\mathrm{OD}_{450}$ values of sera with identical MIF titres are indicated by a solid line, whereas the cut-off point of the ELISA is marked by a dotted line. 
specific serological detection of chlamydial infections [9]. However, the MIF test is difficult to standardise, and is technically demanding. As a result, the use of this assay has been restricted to a relatively small number of qualified research laboratories [34]. The results presented in this paper suggest that a more widely applicable enzyme immunoassay, based upon recombinant MOMP polyantigens, may be helpful in the serodiagnosis of $C$. trachomatis infections. A similar appraoch has been applied successfully in serological detection of cytomegalovirus-specific antibodies in human sera [35]

To evaluate the ELISA with MOMP polyantigens (Fig. 2), 103 sera from different patient groups were selected and grouped according to MIF results (Fig. 3). Almost $80 \%(79.5 \%)$ of C. trachomatis MIF-positive sera (31 of 39), were identified in the assay with the third MOMP polyantigen (antigen 3, Fig. 3), and $<10 \%$ of C. trachomatis MIF-negative sera (6 of 64) were identified as positive with this antigen. The divergent results need to be investigated. However, the detection of a few C. trachomatis MIF-negative sera as positive by ELISA is not due to the presence of cross-reacting C. pneumoniae antibodies. The detection of positive sera by the ELISA was similar in group III ( $C$. pneumoniae-positive by $\mathrm{MIF}$ ) and group IV ( $C$. pneumoniae-negative by MIF) sera (Fig. 3).

The inclusion of additional $C$. trachomatis-specific epitopes in the antigen 1 construct (antigen 2 and antigen 3) clearly increased both sensitivity of specificity of the ELISA assay (Figs 2 and 3). Indeed, the OD mean value of $C$. trachomatis MIF-negative sera is low with antigen 3 (OD 0.43, Fig. 4). A closer look at the three sera of group I not detected by antigen 3 revealed that two had low $C$. trachomatis MIF titres (16 and 64) with high MIF titres against $C$. pneumoniae (both 512) (data not shown). Thus, a certain amount of anti-C. pneumoniae cross-reacting antibodies in the $C$. trachomatis MIF cannot be ruled out because of the presence of the genus-specific LPS epitope in the assay.

When the anti-C. trachomatis IgG antibody levels obtained by ELISA were correlated with the results of the MIF, no strong quantitive correlation was found. This indicates that different antibodies are measured in the two assays. Whereas this ELISA is based upon linear MOMP epitopes, the chlamydial MIF includes detection of conformational MOMP epitopes and epitopes on other Chlamydia species or C. trachomatis serovar specific antigens, or both. The specific antigens involved in the $C$. pneumoniae MIF assay have not been identified.

Even though MIF has been considered the 'gold' standard in chlamydial serology for many years, a recent investigation has shown that the inter-laboratory variation of MIF results is of the order $10-40 \%$ [34].
Therefore, a discrepancy when comparing other tests to the MIF assay is inevitable.

This paper describes the first evaluation of the use of recombinant antigens in the differential serodiagnosis of $C$. trachomatis urogenital infections. The results indicate that recombinant MOMP polyantigens could become a valuable tool in the development of a standardised serological assay for the detection of $C$. trachomatis infections. However, no correlation of ELISA results and disease stages was attempted. This is clearly an important issue, especially in respect to chronic chlamydial infections. To perform such a study, larger, clinically well characterised patient groups need to be tested. Serology may prove to be of importance in the diagnosis of subclinical and persistent $C$. trachomatis infections. The test described in this paper offers practical advantages over MIF including simplicity, low cost and objectivity. However, improvements in the sensitivity and specificity of such a serological test are imperative. Further investigation including detection of serum IgA and IgM is warranted. Perhaps the use of carefully selected peptides in an enzyme immunoassay may prove to be more sensitive in the serodiagnosis of human $C$. trachomatis infections.

This work was supported by EU Grant ERBCHRXCT920040 from the Human Capital and Mobility Program, the Danish Health Research Council (20-3503-1), the Danish Veterinary and Agricultural Research Council (12-1620-1), the Danish Pasteur Association, the University of Aarhus Research Foundation, 'Fonden til Lægevidenskabens Fremme' and 'Nationalforeningen til Bekæmpelse af Lungesygdomme'. We are grateful to Karin Skovgaard Soerensen, Lisbet Wellejus Pedersen and Inger Andersen for excellent technical assistance.

\section{References}

1. Moulder JW. Interaction of chlamydiae and host cells in vitro. Microbiol Rev, 1991; 55: 143-190.

2. Grayston JT, Kuo C-C, Wang S-P, Altman J. A new Chlamydia psittaci strain, TWAR, isolated in acute respiratory tract infections. $N$ Engl J Med 1986; 315: 161-168.

3. Hahn DL, Dodge RW, Golubjatnikov R. Association of Chlamydia pneumoniae (strain TWAR) infection with wheezing, asthmatic bronchitis, and adult-onset asthma. JAMA 1991; 266: 225-230.

4. Kuo CC, Jackson LA, Campbell LA, Grayston JT. Chlamydia pneumoniae (TWAR). Clin Microbiol Rev 1995; 8: 451-461.

5. Saikku P, Leinonen M, Mattila K et al. Serological evidence of an association of novel Chlamydia, TWAR, with chronic coronay heart disease and acute myocardial infarction. Lancet 1988; 2: 983-986.

6. Li D-K, Daling JR, Wang S-P, Grayston JT. Evidence that Chlamydia pneumoniae, strain TWAR, is not sexually transmitted. J Infect Dis 1989, 160: 328-331.

7. Moss TR, Darougar S, Woodland RM, Nathan M, Dines RJ, Cathrine V. Antibodies to Chlamydia species in patients attending a genitourinary clinic and the impact of antibodies to $C$. pneumoniae and $C$. psittaci on the sensitivity and specificity of $C$. trachomatis serology tests. Sex Transm Dis 1993; 20: $61-65$.

8. Friedank HM, Terreri MT, Peter HH, Bredt W. Comparison of serological tests for the detection of antibodies against Chlamydia trachomatis and Chlamydia pneumonaie in rheumatological patients. Int $J$ Med Microbiol Virol Parasitol Infect Dis 1993; 279: 518-525.

9. Wang SP, Grayston JT. Immunologic relationship between genital TRIC, lymphogranuloma venereum, and related organ- 
isms in an new microtitre indirect immunofluoresence test. $\mathrm{Am}$ J Ophthalmol 1970, 70: 367-374.

10. Freidank HM, Herr AS, Jacobs E. Identification of Chlamydia pneumoniae-specific protein antigens in immunoblots. Eur $J$ Clin Microbiol Infect Dis 1993; 12: 947-951.

11. Newhall WJ, Batteiger B, Jones RB. Analysis of the human serological response to proteins of Chlamydia trachomatis. Infect Immun 1982; 38: 1181-1189.

12. Brade H, Brade L, Nano FE. Chemical and serological investigations on the genus-specific lipopolysaccharide epitope of Chlamydia. Proc Natl Acad Sci USA 1987; 84: 2508-2512.

13. Chernesky M, Luinstra $\mathrm{K}$, Sellors $\mathrm{J}$ et al. Can serology diagnose upper genital tract Chlamydia trachmatis infections? Studies on women with pelvic pain, with or without chlamydial plasmid DNA in endometrial biopsy issue. Sex Transm Dis 1998; 25: 14-19.

14. Hanuka N, Glasner M, Sarov I. Detection of $\operatorname{IgG}$ and $\operatorname{IgA}$ antibodies to Chlamydia trachomatis in sera of patients with chlamydial infections: use of immunoblotting and immunoperoxidase assays. Sex Transm Dis 1988; 15: 93-99.

15. Mygind P, Christiansen G, Persson K, Birkelund S. Analysis of the humoral immune response to outer membrane protein 2 . Clin Diagn Lab Immunol 1998; 5: 313-318.

16. Evereet KD, Hatch TP. Architecture of the cell envelope of Chlamydia psittaci 6BC. J Bacteriol 1995; 177: 877-882.

17. Mygind P, Christiansen G, Birkelund S. Topological analysis of Chlamydia trachomatis outer membrane protein 2. J Bacteriol 1998; 180: 5784-5787.

18. Watson MW, Lambden PR, Everson JS, Clarke IN. Immunoreactivity of the $60 \mathrm{kDa}$ cysteine-rich proteins of Chlamydia trachomatis, Chlamydia psittaci and Chlamydia pneumoniae expressed in Escherichia coli. Microbiology 1994; 140: 20032011.

19. $\mathrm{Su} \mathrm{H}$, Caldwell HD. In vitro neutralization of Chlamydia trachomatis by monovalent Fab antibody specific to the major outer membrane protein. Infect Immun 1991; 59: 2843-2845.

20. Batteiger BE, Lin P-M, Jones RB, Van der Pol BJ. Species-, serogroup-, and serovar-specific epitopes are juxtaposed in variable sequence region 4 of the major outer membrane proteins of some Chlamydia trachomatis serovars. Infect Immun 1996; 64: 2839-2841.

21. Jones HM, Schachter J, Stephens RS. Evaluation of the humoral immune response in trachoma to Chlamydia trachomatis major outer membrane proteins by sequence-defined immunoassay. J Infect Dis 1992; 166: 915-919.

22. Campbell LA, Kuo C-C, Wang S-P, Grayston JT. Serological response to Chlamydia pneumoniae infection. J Clin Microbiol 1990; 28: 1261-1264.

23. Christainsen G, Østergard L, Birklund B. Analysis of the Chlamydia pneumoniae surface. In: Orfila $\mathrm{J}$ et al. (eds) Chlamydia infections: Proceedings of the Eighth International Symposium on Human Chlamydial Infections. Italy, Esculapio. 1994: 173-176.

24. Mygind R, Huniche BS, Christiansen G, Persson K, Birkelund $\mathrm{S}$. Detection of Chlamydia trachomatis infections by the use of recombinant MOMP polyantigens. In: Stephens RS et al. (eds) Chlamydial infections: Proceedings of the Ninth International Symposium on Human Chlamydial Infection. International Chlamydia symposium. San Francisco, 1998: 615-618.

25. Persson K, Treharne J. Diagnosis of infection caused by Chlamydia penumoniae (strain TWAR) in patients with 'ornithosis' in southern Sweden 1981-1987. Scand J Infect Dis 1989; 21: 675-679.

26. Sambrook JE, Fritsch EF, Maniatis T (eds). Molecular cloning: a laboratory manual, 2nd edn. Cold Spring Harbor, NY, Cold Spring Harbor Laboratory Press. 1989.

27. Studier FW, Rosenberg AH, Dunn JJ, Dubendorff JW. Use of T7 RNA polymerase to direct expression of cloned genes. In: Goeddel DV (ed) Gene expression technology. (Methods Enzymol 185) San Diego, Academic Press. 1990: 60-89.

28. Morré SA, Moes RM, Van Valkengoed IGM, Boeke JAP, Meijer CJLM, van den Brule AJC. Chlamydia trachomatis genotyping in urine specimens will facilitate large epidiological studies. In: Stephens RS et al. (eds) Chlamydial infections: Proceedings of the Ninth International Symposium on Human Chlamydial Infection. International Chlamydia symposium. San Francisco, 1998: 63-66.

29. Poole E, Lamont I. Chlamydia trachomatis serovar differentiation by direct sequence analysis of the variable segment 4 region of the major outer membrane protein gene. Infect Immun 1992; 60: 1089-1094.

30. Rodridgez P, de Barbeyrac B, Persson K, Dutilh B, Bebear C. Evaluation of molecular typing for epidemiological study of Chlamydia trachomatis genital infections. J Clin Microbiol 1993; 31: 2238-2240.

31. Kaltenboeck B, Heard D, DeGraves FJ, Schmeer N. Use of synthetic antigens improves detection by enzyme-linked immunosorbent assay of antibodies against abortigenic Chlamydia psittaci in ruminants. $J$ Clin Microbiol 1997; 35: 2293-2298.

32. Hochuli E, Bannwarth W, Döbeli H, Gentz R, Stüber D. Genetic approach to facilitate purification of recombinant protein with a novel metal chelate adsorbent. Biotechnology NY 1988; 6: 1321-1325.

33. Yuan Y, Zhang Y-X, Watkins NG, Caldwell HD. Nucleotide and deduced amino acid sequences for the four variable domains of the major outer membrane proteins of the 15 Chlamydia trachomatis serovars. Infect Immun 1989; 57: 1040-1049.

34. Peeling RW, Wang SP, Grayston JT et al. Chlamydia serology: inter-laboratory variation in microimmunofluorescence results. In: Stephens RS et al. (eds) Chlamydial infections: Proceedings of the Ninth International Symposium on Human Chlamydial Infection. International Chlamydia symposium. San Franscisco, 1998: 159-162.

35. Landini MP, Lazzarotto T, Maine GT, Ripalti A, Flanders R. Recombinant mono- and polyantigens to detect cytomegalovirus-specific immunoglobulin $\mathrm{M}$ in human sera by enzyme immunoassay. $J$ Clin Microbiol 1995; 33: 2535-2542. 